\title{
ATRX is a novel progesterone-regulated protein and biomarker of low developmental potential in mammalian oocytes
}

\author{
Lynne C O'Shea ${ }^{1,2}$, Edward Daly ${ }^{1}$, Carmel Hensey ${ }^{3}$ and Trudee Fair ${ }^{1}$ \\ ${ }^{1}$ School of Agriculture and Food Sciences, ${ }^{2}$ School of Medicine, and ${ }^{3}$ School of Bimolecular and Biomedical \\ Science, University College Dublin, Belfield, Dublin 4, Ireland \\ Correspondence should be addressed to L C O’Shea; Email: lynne.oshea@ucd.ie
}

\begin{abstract}
A multi-species meta-analysis of published transcriptomic data from models of oocyte competence identified the chromatin remodelling factor $A T R X$ as a putative biomarker of oocyte competence. The objective of the current study was to test the hypothesis that ATRX protein expression by cumulus-oocyte complexes (COCs) reflects their intrinsic quality and developmental potential. In excess of 10,000 bovine COCs were utilised to test our hypothesis. COCs were in vitro matured (IVM) under conditions associated with reduced developmental potential: IVM in the presence or absence of (1) progesterone synthesis inhibitor (Trilostane); (2) nuclear progesterone receptor inhibitor (Aglepristone) or (3) an inducer of DNA damage (Staurosporine). ATRX protein expression and localisation were determined using immunocytochemistry and Western blot analysis. A proportion of COCs matured in the presence or absence of Trilostane was in vitro fertilised and cultured, and subsequent embryo development characteristics were analysed. In addition, ATRX expression was investigated in $\mathbf{4 0}$ human germinal vesicle-stage COCs. Our results showed that ATRX is expressed in human and bovine germinal vesicle oocytes and cumulus cells. In bovine, expression decreases after IVM. However, this decline is not observed in COCs matured under sub-optimal conditions. Blastocyst development rate and cell number are decreased, whereas the incidence of abnormal metaphase phase spindle and chromosome alignment are increased, after IVM in the presence of Trilostane $(P<0.05)$. In conclusion, localisation of ATRX to the cumulus cell nuclei and oocyte chromatin, after IVM, is associated with poor oocyte quality and low developmental potential. Furthermore, ATRX is dynamically regulated in response to progesterone signalling. Reproduction (2017) 153 671-682
\end{abstract}

\section{Introduction}

The ability of an embryo to develop successfully greatly relies on the quality of the oocyte from which it has been generated. Oocytes progressively acquire developmental competence during oogenesis (oocyte growth) and oocyte maturation (Fair 2010). Currently, it is not possible to accurately predetermine an embryo's ability to provide a viable pregnancy prior to transfer. This remains a major obstacle to overcome in assisted reproduction technology (ART) clinics. Current methods of embryo selection include morphological assessment, metabolomics, time-lapse imaging and preimplantation genetic screening. However, further studies are needed to demonstrate conclusively that these methods yield improved implantation and live birth rates (Bolton et al. 2015). The identification of oocyte biological markers (biomarkers) indicative of high or low developmental potential would permit enhanced embryo selection techniques and improved clinical outcomes. Furthermore, in order to introduce elective single embryo transfer (eSET) and reduce the number of multiple births, many ART centres have adopted extended embryo culture to blastocyst (Day 5 or Day 6), which subjects the embryo to potential epigenetic modifications and imprinting defects that can have a detrimental effect on the future health of the offspring (Shufaro \& Laufer 2013, Petrussa et al. 2014, Whitelaw et al. 2014). A biomarker of oocyte quality would allow for early detection of embryo quality, enabling ESET on Day 3, thus minimising the need for prolonged exposure to in vitro conditions.

In order to facilitate selection of high-quality oocytes, we previously identified potential biomarkers indicative of developmental competence (O'Shea et al. 2012). One such biomarker, ATRX, was associated with decreased oocyte quality in both human and animal (bovine, mouse and monkey) model systems (O'Shea et al. 2012). Importantly, ATRX expression in cumulus cells was also associated with decreased oocyte developmental competence, enabling a potential non-invasive method of detecting oocyte quality i.e. cumulus cell testing. In humans, mutation of the ATRX gene leads to improper methylation of repetitive DNA sequences. In this case, failure to establish the necessary epigenetic modifications 
essential for inactive $\mathrm{X}$ chromosome results in genomic and chromosome instability and leads to X-linked $\alpha$-thalassaemia with mental retardation (ATRX) syndrome (Gibbons et al. 2000). In the mouse, Atrx has been shown to be involved in developmental silencing of imprinted genes and critical for extraembryonic trophoblast formation and subsequent embryo survival (Kernohan et al. 2010). Atrx-deficient mice show altered $X$ chromosome inactivation imprinting patterns in the trophoblast (Baumann \& De La Fuente 2009). During meiosis, ATRX is necessary for heterochromatin formation and maintenance of chromosome stability in order to ensure proper assembly of the metaphase II spindle (De La Fuente et al. 2004, 2015). As a chromatin and epigenetic regulator, ATRX may play a role in maintaining genomic integrity within the oocyte. Chromatin remodelling proteins are known to protect genomic integrity by regulating how chromatin structure changes after DNA damage (Lukas et al. 2011). Also, epigenetic modifications at the chromatin level are thought to preferentially activate the DNA damage checkpoint response and increase DNA repair capacity (Bao et al. 2006, Murga et al. 2007).

Key events in bovine reproduction, such as gestation length, timing of oocyte and embryo development, number of oocytes ovulated and average numbers of gestations per female, recapitulate human biology. In addition, the bovine model provided the research platform for developing human ART; superovulation, IVP, embryo transfer and freezing are based upon many years of research with bovine embryos. We have previously established a robust in vitro model system of reduced bovine oocyte quality by manipulating progesterone (P4) regulation during the critical developmental phase of oocyte maturation (Aparicio et al. 2011). Chemical inhibition of P4 synthesis or blocking the progesterone receptors during in vitro bovine oocyte maturation has a negative effect on oocyte quality, leading to reduced embryonic development (Aparicio et al. 2011, O'Shea et al. 2013). The importance of this model is that it facilitates oocyte maturation, fertilisation and cleavage indistinguishable from the control, non-treated oocytes, with diminished developmental competence only observed later in embryonic development. This is relevant to the human clinical setting where although oocytes and embryos are morphologically normal and of high grade, a successful pregnancy is not always achieved.

In the present study, we analyse both human and bovine cumulus-oocyte complexes (COCs) in order to determine the expression and localisation of ATRX. Furthermore, we utilised both P4-dependent and -independent (DNA damage) model systems of reduced bovine oocyte quality, to elucidate the regulation of ATRX within the COC and determine its association with developmental competence.

\section{Materials and methods}

\section{Bovine oocyte collection}

Meiotic and developmental competence is progressively acquired during the final period of oocyte growth within the early antral follicle (Fair et al. 1997). Growing and fully grown bovine oocytes were collected as described previously (Fair et al. 1995). Briefly, bovine ovaries were sliced using a razor blade, followed by flushing with $1 \mathrm{X}$ PBS to release the growing oocytes. The COCs were denuded of surrounding cumulus cells by repeated pipetting and washing. Individual oocytes were sized using an inverted microscope with an eyepiece micrometre and separated into two size ranges, $101-100 \mu \mathrm{m}$ and $\geq 120 \mu \mathrm{m}$, corresponding to actively growing incompetent and fully grown competent oocytes respectively. For all other investigations, fully grown immature COCs were obtained by aspirating follicles from the ovaries of cattle slaughtered at a local abattoir. In excess of 10,000 bovine oocytes were utilised within the present study. Good-quality COCs were selected and washed, and groups of up to 50 COCs were placed in $500 \mu \mathrm{L}$ maturation medium (TCM-199 supplemented with $10 \%(\mathrm{v} / \mathrm{v})$ foetal calf serum (FCS) and $10 \mathrm{ng} /$ $\mathrm{mL}$ epidermal growth factor) in a four-well dish and cultured at $39^{\circ} \mathrm{C}$ for $24 \mathrm{~h}$ in a humidified atmosphere containing $5 \% \mathrm{CO}_{2}$. Depending on the experiment, in vitro maturation (IVM) was performed in the presence or absence of (1) $1 \mu \mathrm{M}$ progesterone synthesis inhibitor, Trilostane (inhibitor of $3 \beta$-hydroxysteroid dehydrogenase; Stegram Pharmaceuticals Ltd., Surrey, UK) and a matched vehicle control of dimethyl sulfoxide (DMSO) diluted at a final concentration of $0.0001 \%$; (2) $1 \mu \mathrm{M}$ nuclear progesterone receptor inhibitor, Aglepristone (RU 534/Alizine, which blocks nuclear progesterone receptor (PGR) mediated effects of P4, (Teutsch \& Philibert 1994), C\&M Vetlink, Ireland). Aglepristone has a relative binding affinity equal to that of RU486 for the PGR (>9 times greater than that of P4), with negligible affinity for the glucocorticoid receptor (C\&M Vetlink Technical Profile) or (3) $0.5 \mathrm{mM}$ Staurosporine (DNA damage and apoptosis inducing agent). The working concentrations for Trilostane and Aglepristone were determined in previously published experiments as the lowest concentration necessary to cause an effect without inducing toxicity (Aparicio et al. 2011, O'Shea et al. 2013).

\section{Bovine in vitro fertilisation and in vitro culture}

Multiple replicates of in vitro embryo production (IVP) were carried out (a replicate refers to one day of oocyte collection and IVM), as described below, to generate four complete replicates for each of the following analyses: cleavage and blastocyst development at 44 and $192 \mathrm{~h}$ after insemination (hpi), timely development and cell number, incidence of polyspermy, mitotic spindle formation and chromosome alignment, symmetry of cell division and number of cells with pyknotic nuclei (dead cells). Matured COCs were washed four times in PBS and then placed in wells containing $250 \mu \mathrm{L}$ of fertilisation medium. The fertilisation medium consisted of Tyrode medium with $25 \mathrm{mM}$ bicarbonate, $22 \mathrm{mM}$ Na-lactate, $1 \mathrm{mM}$ Na-pyruvate, $6 \mathrm{mg} / \mathrm{mL}$ fatty acid-free bovine serum albumin (BSA) and $10 \mu \mathrm{g} / \mathrm{mL}$ 
heparin-sodium salt (184 U/mg heparin; Calbiochem) per well. Each well was inseminated with frozen-thawed Percollseparated bull sperm (GE Healthcare Bio-sciences) at a concentration of $1 \times 10^{6}$ spermatozoa per millilitre. Plates were incubated for $24 \mathrm{~h}$ at $39^{\circ} \mathrm{C}$ under an atmosphere of $5 \% \mathrm{CO}_{2}$ in air with maximum humidity.

At approximately $20 \mathrm{~h}$ after insemination, presumptive zygotes were denuded by gentle vortexing and washed three times in PBS and twice in culture medium before being transferred to $500 \mu \mathrm{L}$ of synthetic oviduct fluid $+5 \%$ FCS. Dishes were incubated at $39^{\circ} \mathrm{C}$ under an atmosphere of $5 \%$ $\mathrm{CO}_{2}, 5 \% \mathrm{O}_{2}$ and $90 \% \mathrm{~N}_{2}$ with maximum humidity. Cleavage rate was recorded on Day 2 (48 h after insemination), the proportion of 8-cell embryos was recorded on Day 3 and the proportion of embryos reaching the blastocyst stage was recorded from Days 6 to 8 (Day $0=$ day of in vitro fertilisation). Samples were retrieved from IVP at the following time points: telophase of mitosis (6 hpi), 2-cell (24 hpi), 8-cell (72 hpi), morulae (120 hpi/Day 5) and blastocyst (192/Day 8) stages of embryo development.

\section{Human oocyte collection}

Forty germinal vesicle oocytes were obtained from 3 individual patients $(9,10$ and 21 oocytes retrieved from each patient respectively) having one ovary removed for fertility preservation by cryopreservation, prior to gonadotoxic treatment (Andersen et al. 2012). Diagnoses for ovarian cryopreservation included cancer forms not related to any endocrine disorder or ovarian disease. The ethical committee of the municipalities of Copenhagen and Frederiksberg $(\mathrm{H}-2$ 2011-044) approved the study, and informed consent was obtained from all patients.

\section{Immunoblotting, immunoprecipitation and antibodies}

\section{Western blotting}

Five replicate pools of 70 bovine COCs were removed from IVM at 0, 6, 12 or $24 \mathrm{~h}$ and oocytes were denuded of their cumulus cells by gentle pipetting and repeated washing in PBS. Cumulus cells were recovered for analysis by centrifugation at $3000 \mathrm{~g}$ for $3 \mathrm{~min}$. Oocyte and cumulus samples were separately resuspended in lysis buffer (M-PER Mammalian Protein Extraction Reagent; Pierce) supplemented with protease and phosphatase inhibitors (Roche), frozen and thawed three times. Whole oocyte samples were loaded on gels for Western blot analysis (70 oocytes/lane containing $15 \mathrm{mg}$ of protein in a $2-\mu \mathrm{L}$ volume). Cumulus cell samples are then centrifuged for $15 \mathrm{~min}$ at $10,000 \mathrm{~g}$ at $4^{\circ} \mathrm{C}$, and the supernatant was collected for analysis. $15 \mathrm{mg}$ of cumulus cell protein was loaded per lane. Protein concentrations were determined using the Bradford assay (Bradford 1976).

Protein samples were separated according to their apparent molecular mass under denaturing conditions on NuPAGE 4-12\% Tris-Glycine Gels (Invitrogen) and transferred to a PVDF membrane. After blocking in $5 \%$ bovine serum albumin (BSA) in PBS-0.1\% Tween20, membranes were incubated with the appropriate primary antibody, followed by incubation with horse radish peroxidase-conjugated secondary antibodies.
Proteins were visualised using enhanced chemiluminescence Western blotting substrate (Pierce; \#32106). Densitometry was performed using the Imagel program (rsbweb.nih.gov/ij/).

\section{Antibodies}

Anti-ATRX antibody (Abcam; ab54794), anti-GAPDH antibody (CellSignaling; \#3900), anti-pMapk (CellSignaling; \#9101), anti-Caspase 3 (BD Pharmingen; \#559565), Normal Mouse IgG (Abcam; ab37355) and anti-alpha-Tubulin (Sigma-Aldrich; T6074) were used.

\section{Immunofluorescence of oocytes and embryos}

COCs were removed from IVM at 0, 6, 12 or 24h, oocytes were partially denuded of their cumulus cells by gentle pipetting and repeated washing in PBS. Similarly, fertilised eggs, 2-cell, 8-cell, morulae and blastocyst-stage embryos were retrieved from IVP at 6, 24, 72, 120 and 192 hpi. Samples were washed in Sorensons PBS and fixed in 4\% paraformaldehyde for one hour at $4^{\circ} \mathrm{C}$. They were subsequently put through a sequential series of washes in PBS containing 1\% Triton X100 and 3\% BSA (PBSTx), followed by blocking for $2 \mathrm{~h}$ at room temperature $\left(\mathrm{RT}^{\circ} \mathrm{C}\right)$ in PBSTx containing $5 \%$ goat serum to avoid nonspecific binding of the antibodies.

COCs were subsequently incubated with ATRX primary antibody at a concentration of $1 / 500$ overnight at $4^{\circ} \mathrm{C}$, a matched mouse IgG antibody was used as a negative control. Embryo samples were incubated with alpha-tubulin primary antibody at a concentration of $1 / 50$ overnight at $4^{\circ} \mathrm{C}$. After primary antibody incubation, COC and embryos were washed repeatedly in PBSTx $(3 \times 15 \mathrm{~min}$ and one by $1 \mathrm{~h}$, washes $)$, after which, samples were incubated with the secondary antibody (Alexa Fluor 568 goat anti-mouse 1:1000) for $4 \mathrm{~h}$ at $4^{\circ} \mathrm{C}$. Excess labelling was removed by repeated washing in PBSTx, and COCs/embryos were mounted on a glass slide, immersed in mounting medium containing 40,60-diamidino2-phenylindole (DAPI; $1 \mu \mathrm{g} / \mathrm{mL}$ ) for DNA visualisation and covered with a glass cover slip. Three replicates of 40 oocytes per group were analysed. Four replicates, totalling approximately 40 embryos per time point (Table 1), were analysed.

\section{Image acquisition and analysis}

Immunolabelled oocytes and embryos were analysed using the Olympus FLUOVIEW FV1000 confocal laser scanning microscope equipped with a 40×/NA 1.15 water immersion objective and a $60 \times / 1.35$ NA oil immersion objective with zoom function. The fluorochrome was excited using the appropriate combination of excitation and barrier filters and laser lines for DAPI $(405 \mathrm{~nm})$ and Alexa Fluor $568(543 \mathrm{~nm})$. The settings were kept constant during image acquisition of all samples. For COC ATRX expression and localisation analysis, a normal mouse IgG antibody was used as the negative control to establish a pixel intensity that eliminated $99 \%$ of the background signal. Background fluorescence was then subtracted by applying this threshold to all images. For embryo analysis, the number of blastomeres was counted in each 
Table 1 Effect of P4 synthesis inhibition on occurrence of spindle and cellular abnormalities.

\begin{tabular}{|c|c|c|c|c|c|c|c|c|c|c|}
\hline Time & Treatment & Reps & $n$ & $\begin{array}{c}\text { Observed } \\
\text { spindles }\end{array}$ & $\operatorname{Good}(\%)$ & $\begin{array}{c}\text { Abnormal } \\
(\%)\end{array}$ & $\begin{array}{l}\text { Polyspermy } \\
(\%)\end{array}$ & $\begin{array}{l}\text { Timely development } \\
(\%)\end{array}$ & $\begin{array}{c}\text { Asymmetrical division } \\
(\%)\end{array}$ & $\begin{array}{c}\text { Dead cells } \\
(\%)\end{array}$ \\
\hline \multirow[t]{2}{*}{6 hpi } & Control & 4 & 32 & 32 & $28(87.5)$ & $4(12.5)^{\mathrm{a}}$ & $\mathrm{N} / \mathrm{A}$ & $\mathrm{N} / \mathrm{A}$ & N/A & $\mathrm{N} / \mathrm{A}$ \\
\hline & Trilostane & 4 & 32 & 32 & $20(62.5)$ & $12(37.5)^{b}$ & $\mathrm{~N} / \mathrm{A}$ & $\mathrm{N} / \mathrm{A}$ & $\mathrm{N} / \mathrm{A}$ & $\mathrm{N} / \mathrm{A}$ \\
\hline \multirow[t]{2}{*}{24 hpi } & Control & 4 & 54 & 3 & 3 (100) & $0(0)^{\mathrm{a}}$ & $5(9)$ & $51(98)$ & $\mathrm{N} / \mathrm{A}$ & $\mathrm{N} / \mathrm{A}$ \\
\hline & Trilostane & 4 & 42 & 3 & $0(0)$ & $3(100)^{b}$ & $11(26)$ & $33(76)$ & N/A & $\mathrm{N} / \mathrm{A}$ \\
\hline \multirow[t]{2}{*}{ Day 3} & Control & 5 & 39 & 9 & $8(89)$ & $1(11)^{\mathrm{a}}$ & N/A & $17(56)$ & $6(15)$ & $8(21)$ \\
\hline & Trilostane & 5 & 60 & 13 & $6(46)$ & $7(54)^{b}$ & $\mathrm{~N} / \mathrm{A}$ & $34(43)$ & $20(33)$ & $24(40)$ \\
\hline \multirow[t]{2}{*}{ Day 5} & Control & 5 & 52 & 17 & 15 (88) & $2(12)^{\mathrm{a}}$ & $\mathrm{N} / \mathrm{A}$ & $23(44)$ & $19(37)$ & $15(29)$ \\
\hline & Trilostane & 5 & 52 & 20 & $9(45)$ & $11(55)^{b}$ & $\mathrm{~N} / \mathrm{A}$ & $17(33)$ & $18(35)$ & $22(42)$ \\
\hline \multirow[t]{2}{*}{ Day 8} & Control & 4 & 37 & 18 & 16 (89) & $2(11)^{\mathrm{a}}$ & $\mathrm{N} / \mathrm{A}$ & $34(92)^{\mathrm{a}}$ & $4(11)$ & $0(0)^{\mathrm{a}}$ \\
\hline & Trilostane & 4 & 27 & 18 & $10(55)$ & $8(45)^{b}$ & $\mathrm{~N} / \mathrm{A}$ & $17(63)^{b}$ & $5(19)$ & $3(17)^{b}$ \\
\hline
\end{tabular}

${ }^{a, b}$ Data with different letters indicate significant differences between treatments $(P<0.05)$.

embryo at each stage of development. Embryo development was expected to proceed at a rate of one cleavage division per cell, per $24 \mathrm{~h}$. Therefore, embryos were expected to have developed to 2-cells, 4-cells, 8-cells, morula and blastocyst stages by 24, 28 and 72, 120 and 190 hpi respectively. The symmetry of cell division was assessed and asymmetrical division was noted, if blastomeres were grossly different in size within an embryo. The number of picnotic nuclei was counted in each embryo. The chromatin and spindle arrangement of each blastomere at metaphase of mitosis was scrutinised using z-slice confocal imaging $(1 \mu \mathrm{m}$ slices) and $3 \mathrm{D}$ projection. Embryos were deemend to present abnormal metaphase plates if the number of spindle poles exceeded 2 and if chromosomes were visualised outside the equatorial alignment.

\section{Statistical analysis}

The densitometry data from the Western blots were analysed using ANOVA followed by Scheffe's $t$-test. COC statistical analyses were carried out using GraphPad Prism 6. Embryo cleavage rate, blastocyst development and cell number between treatments were analysed by using the Mixed Procedure in SAS. Logistic regression analysis was conducted to determine the probability of abnormal spindle formation, asymmetrical division, polyspermy and timely development using SAS software. Differences between COC and embryo groups were considered significant when $P$ values were less than 0.05 .

\section{Results}

\section{Localisation of ATRX protein in human and bovine cumulus-oocyte complexes}

ATRX was found to be localised to the nucleus of bovine germinal vesicle (GV) oocytes and to the nuclei of their surrounding cumulus cells (Fig. 1A and Supplementary Figure $1 \mathrm{~A}$ (please see section on Supplementary data at the end of the article)). This expression and localisation was observed in human oocytes and cumulus cells (Fig. 1B and Supplementary Figure 1B).

Western blot analyses determined bovine oocyte ATRX protein expression to decrease on completion of the oocyte growth phase, i.e., in line with acquisition of developmental competence, with the lowest expression observed in oocytes with a diameter of greater than $120 \mu \mathrm{m}$ (Fig. 2A). In addition, ATRX levels where shown to decrease further during IVM of oocytes (Fig. 2B). ATRX protein expression also decreased in the companion cumulus cells that surrounded the bovine oocytes (Fig. 2C).

\section{The effect of $P 4$ regulation on ATRX protein expression during bovine oocyte maturation}

In contrast to the decreased expression observed in COCs during normal maturation, COCs matured in the presence of Trilostane (P4 synthesis inhibition) displayed high levels of ATRX protein expression throughout maturation in both the oocyte and the companion cumulus cells (Fig. 3A and B and Supplementary Figure 1A). This profile of ATRX protein expression was paralleled in COCs matured in the presence of Aglepristone (PGR antagonist), with ATRX expression levels maintained throughout IVM in both the oocyte and the cumulus cells (Fig. 3C and D).

In addition, although oocytes matured in the presence of both Trilostane and Aglepristone successfully completed maturation and developed a metaphase plate, they displayed high levels of apoptosis, i.e., active Caspase-3 expression (Fig. 3E).

\section{The effect of $P 4$ regulation on ATRX localisation during bovine oocyte maturation}

ATRX was found to be localised to the nucleus of bovine GV (0h) and GVBD (6h) oocytes analysed by immunofluorescent whole-mount staining (Fig. 4A). ATRX expression within the oocyte decreased throughout the maturation process and was not detected in immunostained MI (12-h) and MII (24-h) bovine oocytes. However, ATRX was expressed consistently in the nucleus of oocytes matured in the presence of both Trilostane and Aglepristone, maintaining expression and nuclear localisation at GVBD (6h), MI (12h) and MII (24h). 
A
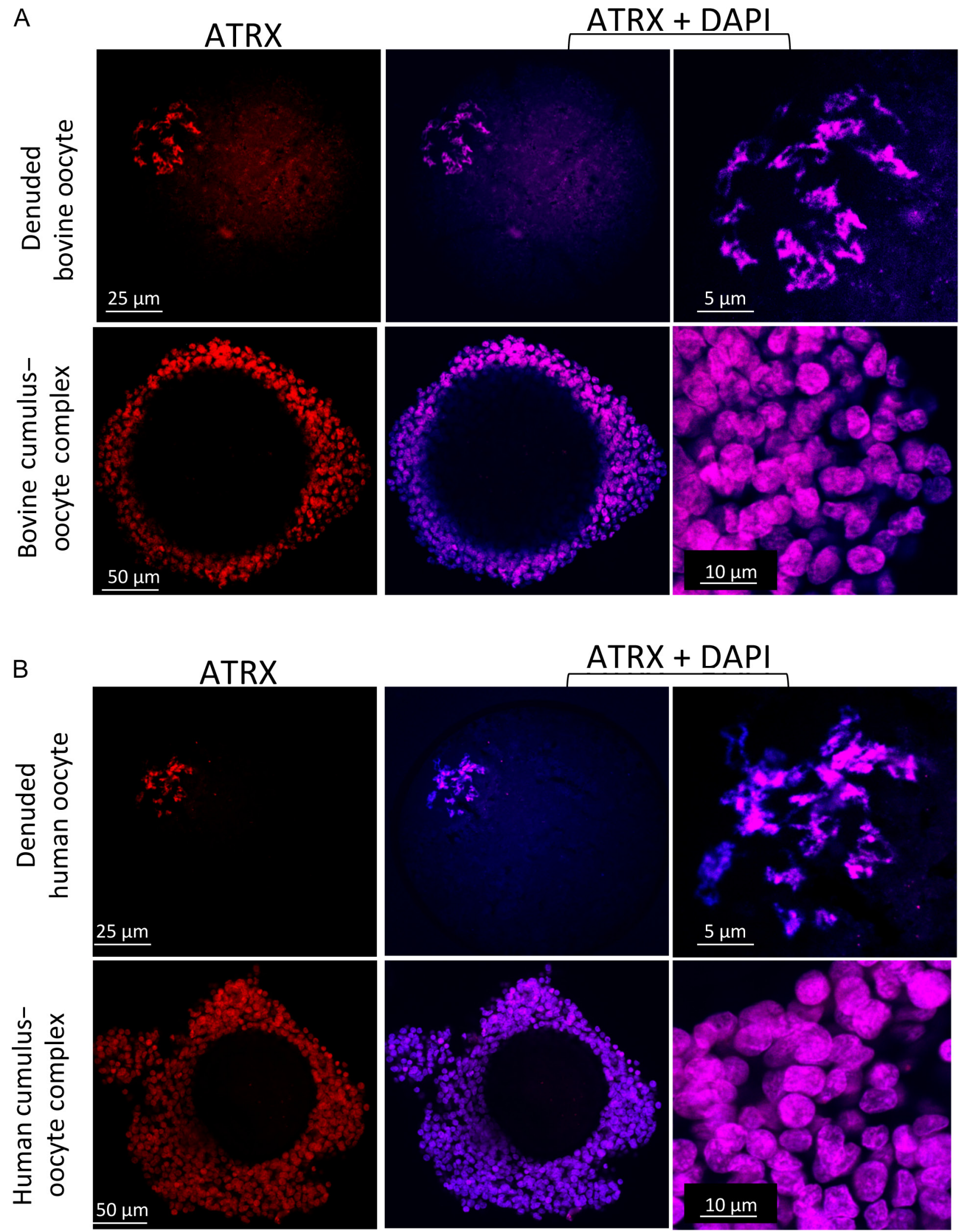

Figure 1 ATRX expression and localization in the human and bovine germinal vesicle oocytes and companion cumulus cells. Confocal laser scanning micrographs showing immunofluorescent detection of ATRX in (A) human oocytes and cumulus-oocyte complexes (3 patients; 40 oocytes total) and (B) bovine oocytes and cumulus-oocyte complexes (3 reps of 30 oocytes per group). ATRX was visualised in red, and DNA was visualised in blue (DAPI). 


\section{A Oogenesis: bovine oocyte growth}

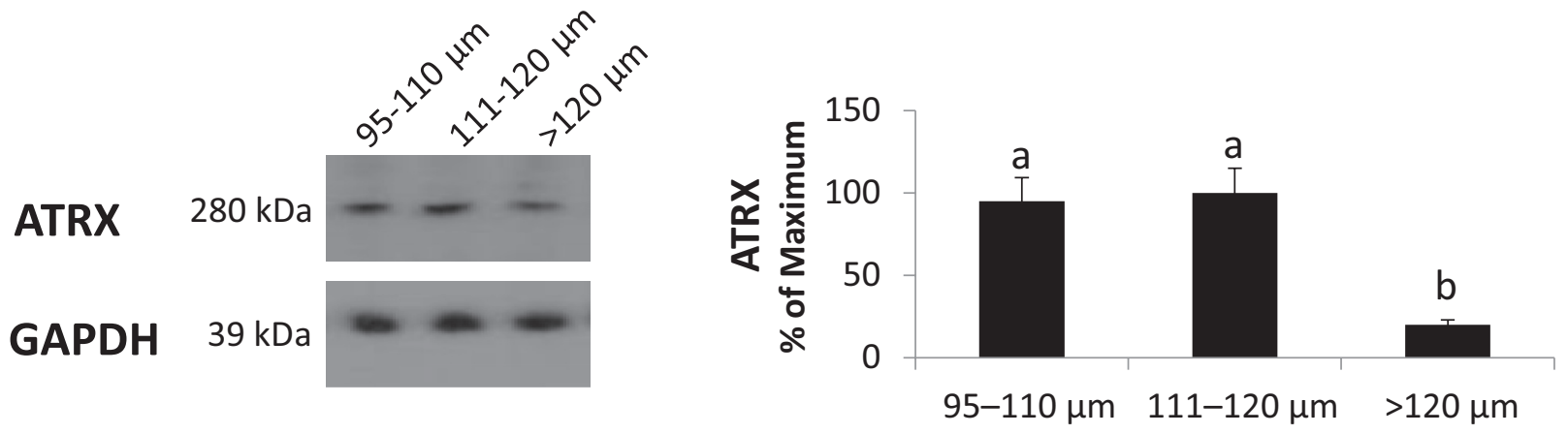

\section{B Oocyte maturation: bovine oocytes}

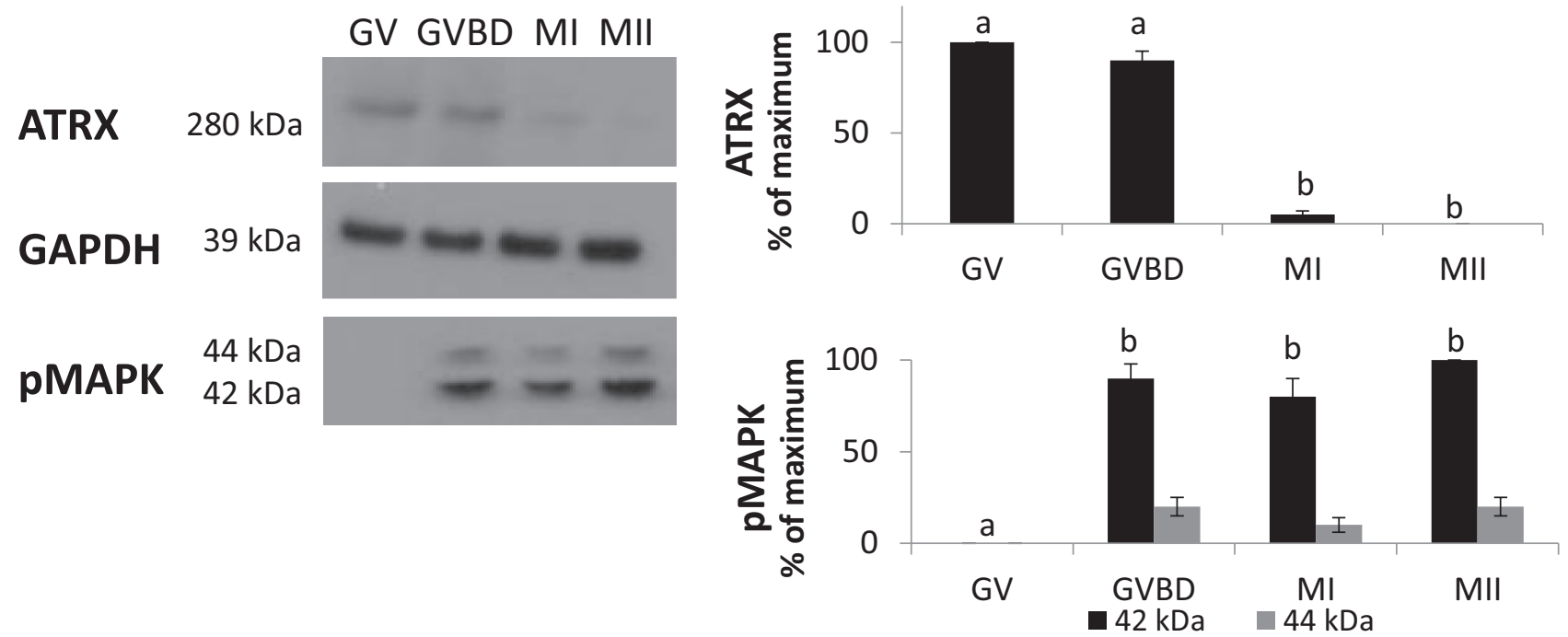

\section{Oocyte maturation: bovine cumulus cells}

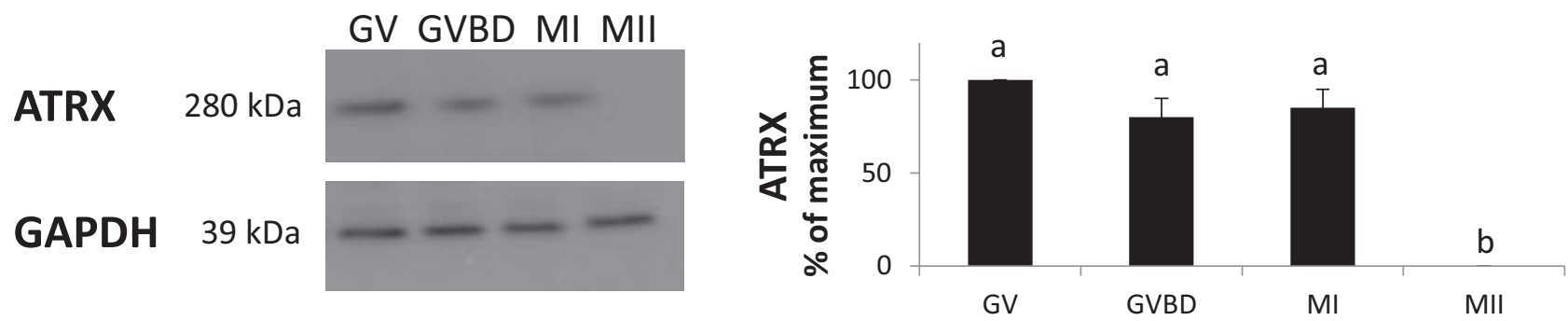

Figure 2 ATRX expression in bovine oocytes during oogenesis and in vitro oocyte maturation. Representative Western blot analysis of ATRX protein expression during (A) bovine oogenesis (59-69 bovine oocytes were loaded per lane, $n=3$ ). (B) Bovine oocytes and (C) the corresponding bovine cumulus cells undergoing meiotic maturation. Germinal vesicle breakdown was determined by pMAPK expression. GAPDH was used as a loading control. GV: germinal vesicle (bovine $0 \mathrm{~h}$ ), GVBD: germinal vesicle breakdown (bovine $6 \mathrm{~h}$ ), MI: metaphase I (bovine $12 \mathrm{~h}$ ), MII: Metaphase II (bovine $24 \mathrm{~h}$ ). (75 bovine oocytes were loaded per lane, $n=5$ ). Densitometry normalised to GAPDH, columns represent average, error bars represent the standard deviation. $a, b, c$ Superscripts of different alphabetic characters indicate significant differences $(P<0.05)$ between groups, whereas presence of identical characters indicates lack of significant differences. 

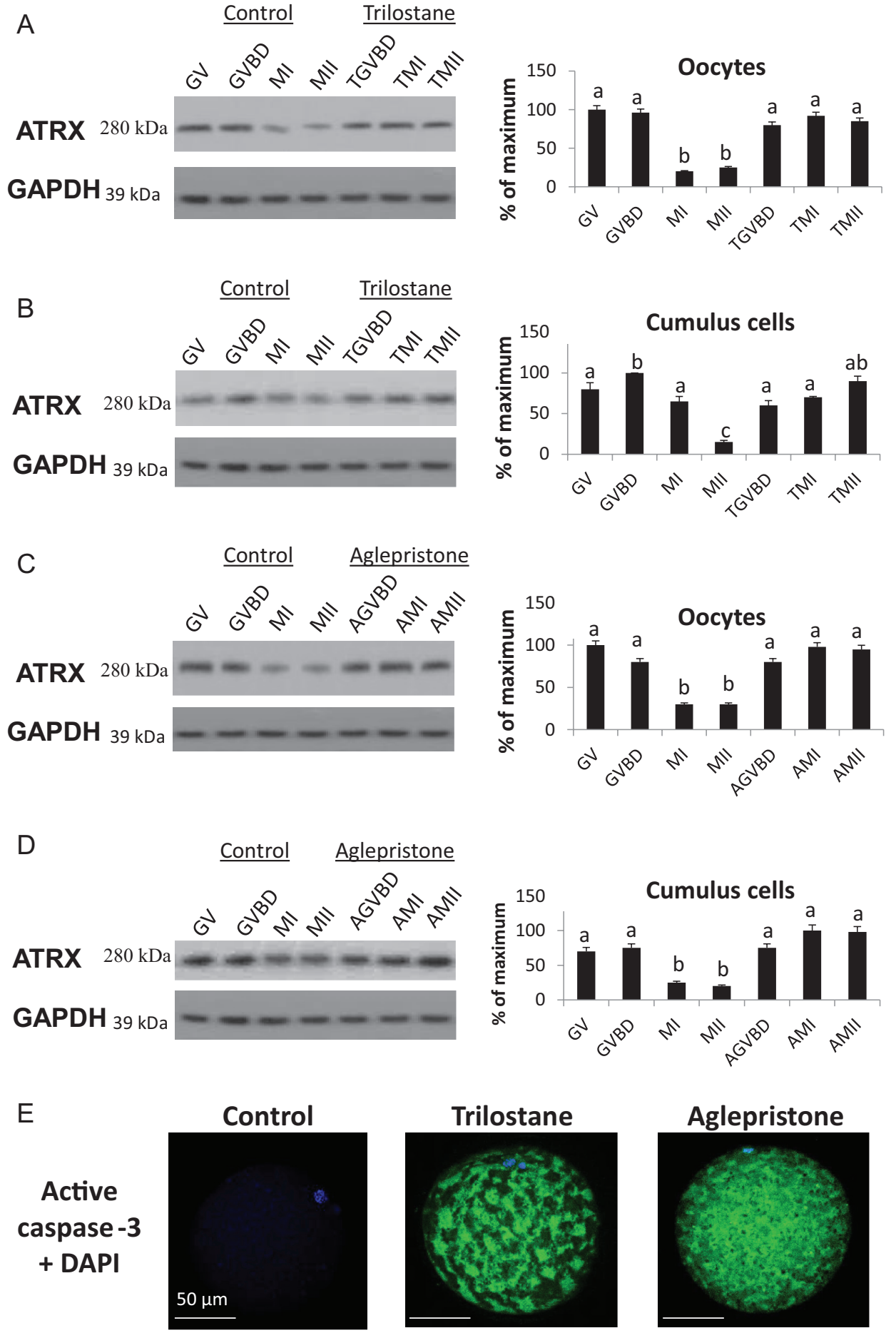

Figure 3 The effect of progesterone regulation on ATRX expression during bovine in vitro maturation. Bovine cumulus-Oocyte complexes (COCs) were matured under control conditions or in the presence of the progesterone synthesis inhibitor Trilostane (' $\mathrm{T}^{\prime}$ prefix) (model of decreased developmental competence) or nuclear progesterone receptor inhibitor Aglepristone (' $\mathrm{A}$ ' prefix). Shown are representative Western blot analyses at 0 (GV), 6 (GVBD), $12(\mathrm{MI})$ and 24 (MII) hours of in vitro oocyte maturation in (A) Trilostane-treated bovine oocytes or (B) Trilostane-treated cumulus cells, (C) Aglepristone-treated bovine oocytes or (D) Aglepristone-treated cumulus cells. Columns represent average protein content, error bars represent the standard deviation for $n=3$, with loading normalised to GAPDH. ${ }^{a, b, c}$ Superscripts of different alphabetic characters indicate significant differences $(P<0.05)$ between groups, whereas the presence of identical characters indicates lack of significant differences. GV: germinal vesicle, GVBD: germinal vesicle breakdown, MI: metaphase I, MII: metaphase II. (E) Confocal laser scanning micrographs showing immunofluorescent detection of active caspase 3 in bovine oocytes after in vitro maturation under control, Trilostane- or Aglepristonesupplemented conditions. 
A

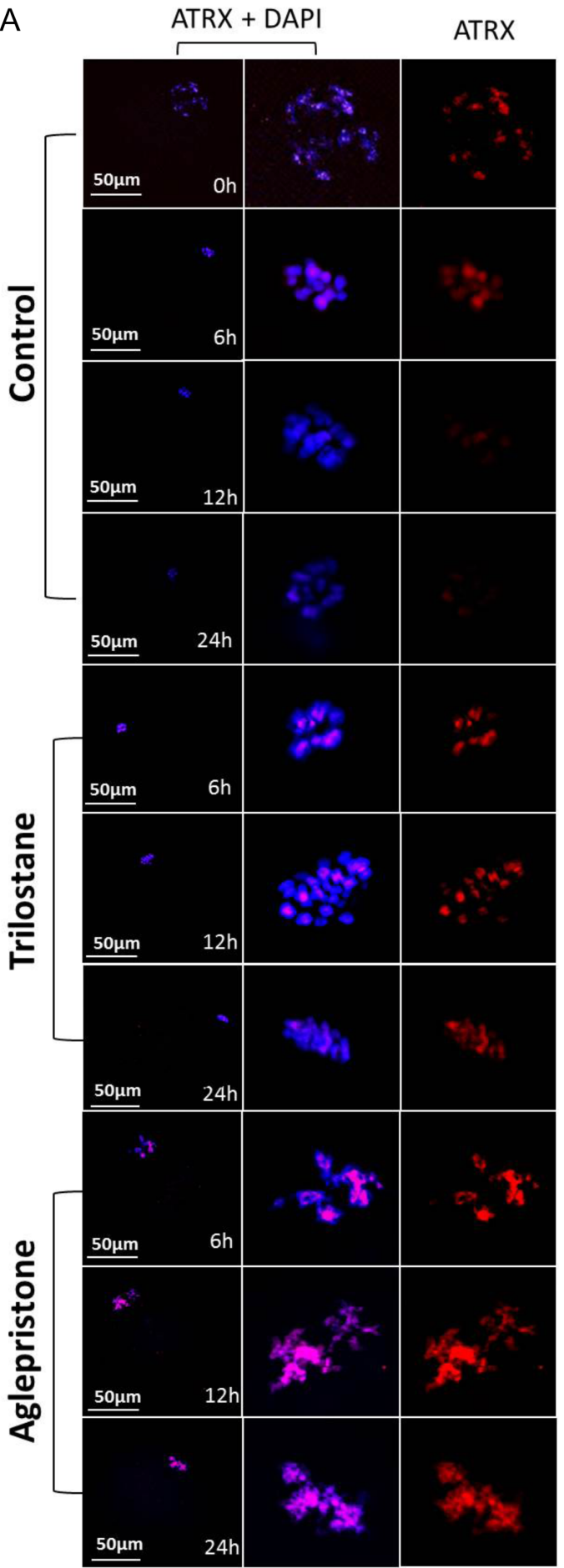

B

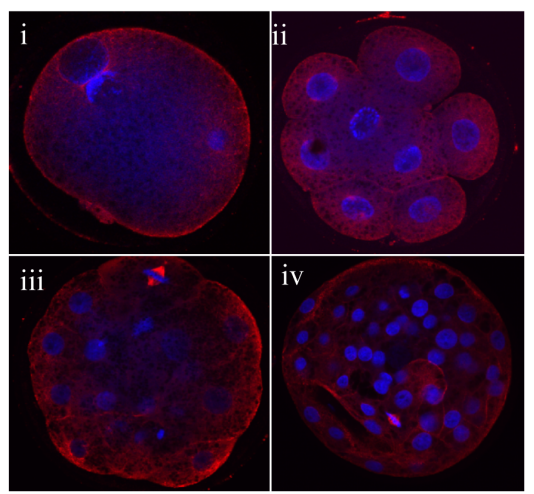

C

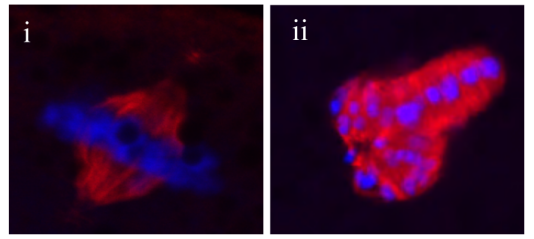

D 100

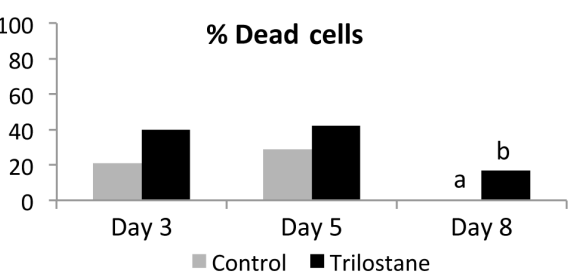

E

\% Spindle Abnormalities

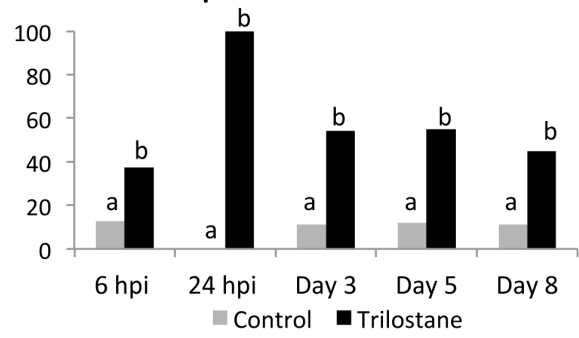

F $100 \quad$ \% Development

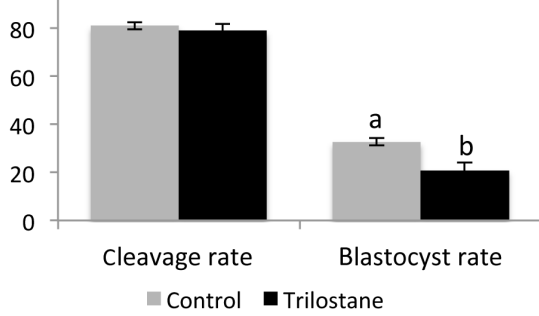

Figure 4 ATRX localisation in bovine oocytes and embryonic development. (A) Confocal laser scanning micrographs showing immunofluorescent detection of ATRX in bovine oocytes ( 3 reps of 30 oocytes per group) during in vitro oocyte maturation under control conditions, in the presence of Trilostane or in the presence of Aglepristone. $0 \mathrm{~h}$ : germinal vesicle oocyte, $6 \mathrm{~h}$ : germinal vesicle breakdown, $12 \mathrm{~h}$ : Metaphase l, $24 \mathrm{~h}$ :

Metaphase II. ATRX was visualised in red and DNA was visualised in blue (DAPI). Bar $=50 \mu \mathrm{m}$. (B) Polyspermy, $24 \mathrm{~h}$ after insemination, was assessed using DAPI (blue) to stain nuclear material; whereas alpha-tubulin was visualised in red (i). Cell number and asymmetry were assessed at days 3, 5 (iii) and 8 (iv) after insemination. (C) Percentage (\%) cell death was measured at Days 3, 5 and 8 of bovine embryonic development. a,bSuperscripts of different alphabetic characters indicate significant differences $(P<0.05)$ between groups. (D) Spindle arrangements were assessed for abnormal alignment of chromosomes using DAPI to label DNA (blue) and $\alpha$-tubulin to indicate spindle tubules (red). Chromosomes should be aligned in the same plane (i) and not lagging. (E) Percentage (\%) spindle abnormality was measured at $6 \mathrm{hpi}, 24 \mathrm{hpi}$ and Days 3,5 and 8 of bovine embryonic development. ${ }^{\mathrm{a}, \mathrm{b}}$ Superscripts of different alphabetic characters indicate significant differences $(P<0.05)$ between groups. 


\section{The effect of P4 synthesis inhibition on embryonic development}

Blastocyst development rate was found to be decreased in Trilostane-treated COCs $(21 \%)$ compared to that in control-treated COCs (33\%) $(P<0.05)$ (Fig. 4F), corresponding to our previously published work (Aparicio et al. 2011, O'Shea et al. 2013). However, there was no effect on cleavage rates between the control and Trilostane treatment groups $(81 \%$ and $79 \%$ respectively).

Additionally, polyspermy, cell number and asymmetry were counted in all embryos and used as indicators for development (Fig. 4B and Table 1). On Day 8, there was an effect by treatment on cell number comparing control $(97.9 \pm 3.1)$ and Trilostane $(81.9 \pm 3.6)(P<0.001)$ (Fig. 4C). No effect was observed on polyspermy or cell symmetry. At all time points, 6h, 24h, Day 3, Day 5 and Day 8 , there was a greater occurrence of abnormal metaphase phase spindle and chromosome alignment in Trilostane-treated samples compared to that of control samples (Fig. 4D, E and Table 1) $(P<0.05)$.

\section{ATRX protein expression and localisation in DNA-damaged oocytes}

COCs matured in the presence of Staurosporine (DNA damage inducer via double-strand breaks) displayed increased expression of ATRX protein compared to COCs matured under control conditions. This increase in expression was observed in both oocytes (Fig. 5A) and the companion cumulus cells (Fig. 5B). This increase in ATRX protein expression in Staurosporine-treated COCs corresponded to the induction of active caspase-3 expression, as indicated by both Western blot analysis (Fig. 5A and B) and immunostaining (Fig. 5C).

\section{Discussion}

In the present study, we determined ATRX protein expression and localisation to be conserved between human and bovine immature COCs. In both species, ATRX protein is localised to the chromosomal area of the GV oocyte. Furthermore, ATRX is highly detectable in the cumulus cells, which surround both the human and bovine oocyte, providing a potential non-invasive method to assess the oocyte quality, particularly in the case of single oocyte/embryo IVP systems. Analysis of growing and fully grown bovine oocytes revealed a decrease in ATRX expression on completion of the growth phase, with a further decline after progression through meiotic maturation. The period of antral follicle oocyte growth in cattle is characterised by high levels of transcriptional activity and the establishment of the maternal imprints (Fair et al. 1995, 1997, O'Doherty et al. 2012). The abundant ATRX expression during the growth phase may reflect its multiple roles and interactions in the regulation of gene expression. For example, ATRX directly binds H3K9me3, which facilitates the recruitment of Daxx and subsequent deposition of the H3.3 histone variant at imprinted differentially methylated regions (DMRs). This ATRX/ Daxx/H3.3 complex acts to maintain silencing at the DMR during transcription (see Voon \& Gibbons 2016, for review).

The bulk of information concerning the function of ATRX in mammalian oocytes has focused on events after the resumption of meiosis. Studies in mice have clearly demonstrated the importance of ATRX during oocyte meiotic maturation through its involvement in chromosome alignment (De La Fuente et al. 2004, 2012, 2015, Baumann et al. 2010). ATRX dysregulation or inhibition is linked to spindle defects, in addition to chromosomal alignment and segregation problems during mitosis and meiosis (Ritchie et al. 2008, Seah et al. 2008, Baumann et al. 2010). In the current study, bovine COCs matured in the presence of Trilostane (absence of P4), displayed an increased incidence of spindle abnormalities during embryogenesis. However, in contrast to the functional mouse studies cited previously in which ATRX expression was inhibited or reduced, ATRX expression and localisation to chromatin was increased in both the oocyte and cumulus cells. Similarly, findings of increased pericentromeric ATRX increased spindle abnormalities, and unaligned chromosomes were recently described in mouse oocytes after postovulatory ageing (Trapphoff et al. 2016). Thus, it would appear that in matured oocytes, increased localisation of ATRX to the chromatin, particularly to the peri-centromere, reflects the activation of a DNA damage response. Indeed, ATRX protein expression appears to be linked to apoptosis within the oocyte and the cumulus cells, as evidenced by our current finding of increased chromatin ATRX accumulation after Staurosporine induction of active Caspase-3 expression in bovine COCs and earlier findings of activation of Caspase- 3 expression in COCs matured under conditions blocking P4 synthesis and PGR signalling (O'Shea et al. 2013).

Here, we determined ATRX to be a marker of poor oocyte quality in both P4 and non-P4-regulated models of reduced bovine oocyte competence. ATRX showed increased protein expression, in both oocytes and cumulus cells after Trilostane and Aglepristone treatment (P4 regulated reduced developmental competence models) during bovine IVM. Therefore, ATRX may play a role in $\mathrm{P} 4$ regulation of oocyte quality via the PGRs, particularly in the transcriptionally active cumulus cells. P4 is known to induce gene transcription by signalling through the PGRs. P4 binding causes conformational changes in the PGRs that induces receptor dissociation from the inhibitory chaperone complex. This allows for receptor homodimerisation and binding to specific progesterone response elements (PREs) within the promoter of target genes (Tsai \& O'Malley 1994, 
A

ATRX

ACTIVE

CASPASE-3

GAPDH

\section{GV MII SMII}

$280 \mathrm{kDa}$

17 kDa

39 kDa
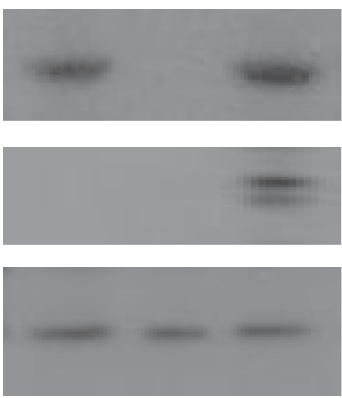

B

ATRX

ACTIVE

CASPASE-3

GAPDH

\section{GV MII SMII}

$280 \mathrm{kDa}$

$17 \mathrm{kDa}$

39 kDa
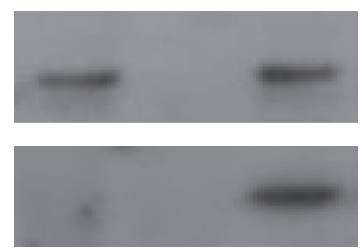

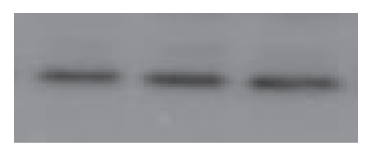

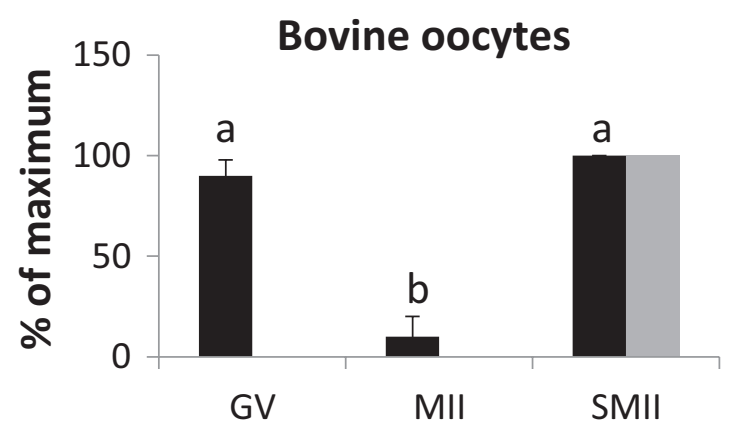

- ATRX Active caspase-3

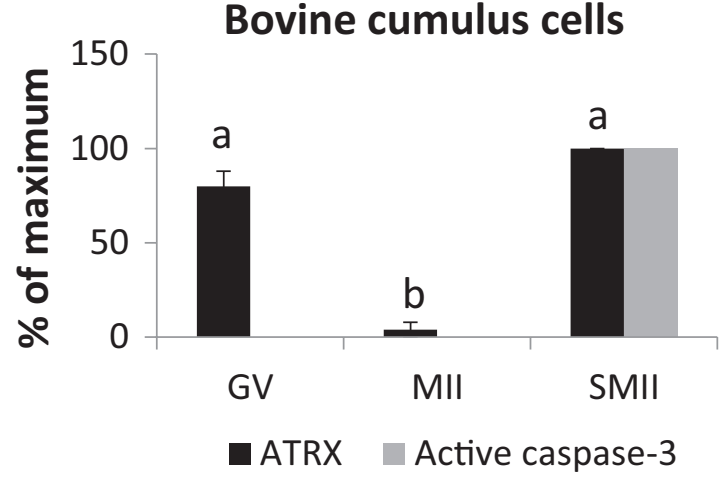

C Active

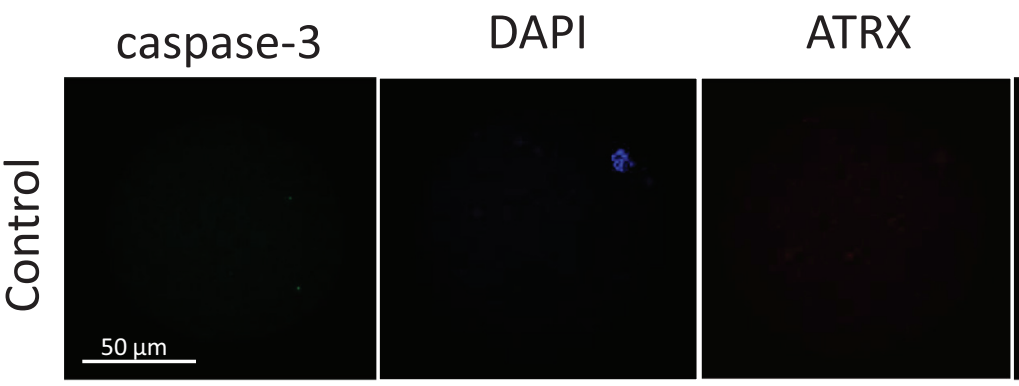

Merge

Merge x5
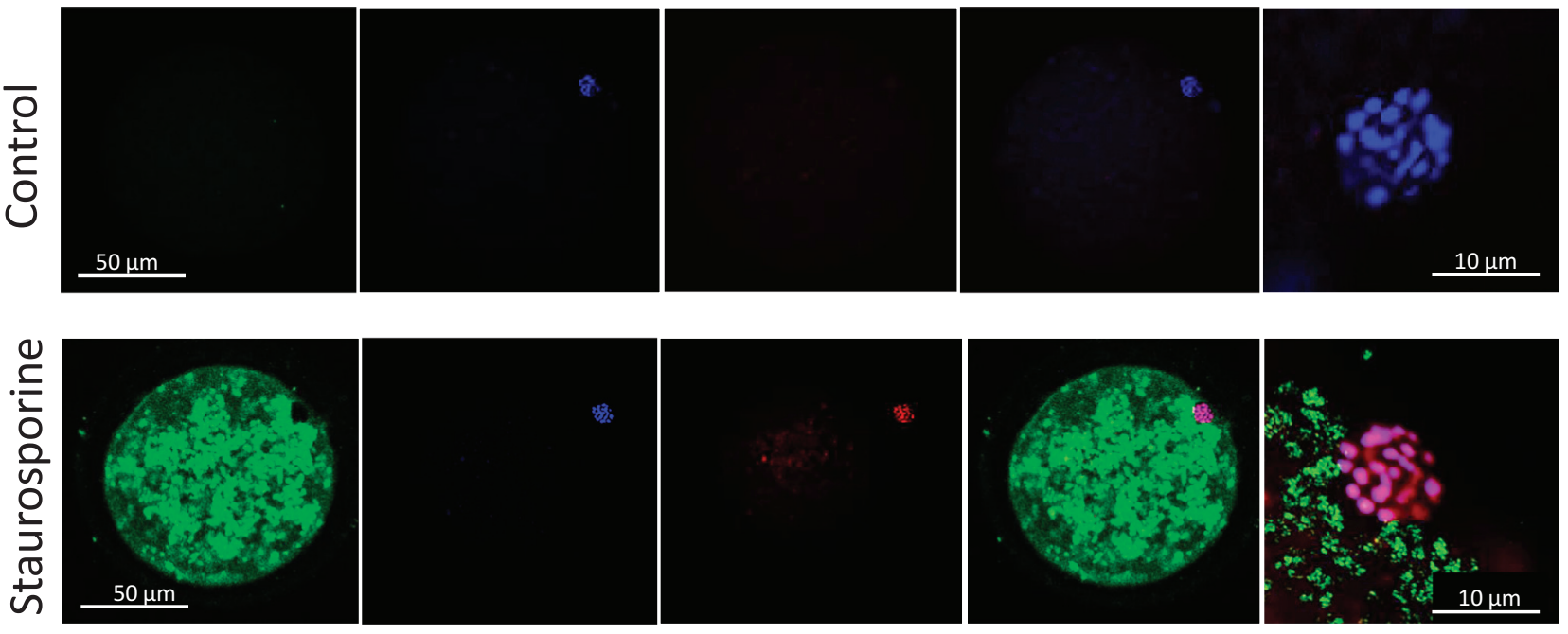

Figure 5 ATRX protein expression is regulated in response to stress. Western blot analysis of ATRX and active Caspase- 3 expression was performed in (A) bovine oocytes and (B) cumulus cells before maturation (GV), matured under normal in vitro maturation conditions (MII) or supplemented with Staurosporine (SMII) during maturation. Densitometry normalised to GAPDH, columns represent average, error bars represent the standard deviation for $n=4$, a,b,cSuperscripts of different alphabetic characters indicate significant differences $(P<0.05)$ between groups, whereas the presence of identical characters indicates lack of significant differences. (C) Confocal laser scanning micrographs showing immunofluorescent detection of ATRX and active Caspase-3 in bovine oocytes (3 reps of 30 oocytes per group) during in vitro oocyte maturation under control conditions or in the presence of Staurosporine (DNA damage). 
Cheung \& Smith 2000). DNA-bound receptors subsequently increase or decrease the rates of gene transcription. In silico analysis of the promoter regions of these genes found ATRX to contain a potential progesterone receptor-binding element consensus sequence (www.genomatix.de). ATRX has previously been identified as being steroid hormone regulated, with ATRX and the androgen receptor been shown to physically interact in the testis and in the Sertoli cell line, TM4 (Bagheri-Fam et al. 2011). It is currently unknown how the regulation of ATRX corresponds to developmental competence. Greater knowledge of the mechanism by which ATRX is regulated within the cumulus-oocyte complex, including P4 and apoptotic regulation, could lead to improvements in both oocyte selection and oocyte quality. The fact that ATRX is dynamically regulated during P4 synthesis and PGR inhibition may provide a way to pharmacologically improve oocyte culture conditions in vitro.

The results obtained in this study suggest that ATRX could be used to discriminate between growing and fully grown oocytes, between meiotically immature and mature oocytes and between morphologically normal COCs with poor developmental potential and their more competent counterparts. Furthermore, as ATRX expression is detectable in the cumulus cells that surround the oocyte, non-invasive screening could be carried out without risking damage to the oocyte. However, protein expression analysis and quantification involves processing substantial sample material through lengthy methodologies, which is not compatible with clinical IVP routines. Therefore, much work must be carried out to determine ATRX expression cut-off values relative to growth, meiotic maturation and competence and rapid analysis methods need to be developed before ATRX can be used in a clinical setting.

\section{Supplementary data}

This is linked to the online version of the paper at http://dx.doi. org/10.1530/REP-16-0443.

\section{Declaration of interest}

The authors declare that there is no conflict of interest that could be perceived as prejudicing the impartiality of the research reported.

\section{Funding}

This work was supported by Science Foundation Ireland grant 07/SRC/B1156 and Irish Research Council New Foundations Award (the opinions, findings and conclusions or recommendations expressed in this material are those of the authors and do not necessarily reflect the views of the Science Foundation Ireland or Irish Research Council).

\section{Author contribution statement}

Trilostane was kindly supplied by $\operatorname{Dr}$ M Parrish, Stegram Pharmaceuticals Ltd, UK. Thanks to Mary Wade for her technical support in the IVF laboratory. Thanks to Prof. Claus Andersen, Dr Stine Kristensen and all in the Copenhagen Laboratory of Reproductive Biology for the collection of samples and their technical assistance.

\section{Acknowledgements}

This work was supported by Science Foundation Ireland grant 07/SRC/B1156 and Irish Research Council New Foundations Award. The authors declare that there are no conflicts of interest.

\section{References}

Andersen CY, Kristensen SG, Greve T \& Schmidt KT 2012 Cryopreservation of ovarian tissue for fertility preservation in young female oncological patients. Future Oncology 8 595-608. (doi:10.2217/fon.12.47)

Aparicio IM, Garcia-Herreros M, $\mathbf{O}^{\prime}$ Shea LC, Hensey C, Lonergan P \& Fair T 2011 Expression, regulation, and function of progesterone receptors in bovine cumulus oocyte complexes during in vitro maturation. Reproductive Biology 84 910-921. (doi:10.1095/ biolreprod.110.087411)

Bagheri-Fam S, Argentaro A, Svingen T, Combes AN, Sinclair AH, Koopman P \& Harley VR 2011 Defective survival of proliferating Sertoli cells and androgen receptor function in a mouse model of the ATR-X syndrome. Human Molecular Genetics 20 2213-2224. (doi:10.1093/ hmg/ddr109)

Bao S, Wu Q, McLendon RE, Hao Y, Shi Q, Hjelmeland AB, Dewhirst MW, Bigner DD \& Rich JN 2006 Glioma stem cells promote radioresistance by preferential activation of the DNA damage response. Nature $\mathbf{4 4 4}$ 756-760. (doi:10.1038/nature05236)

Baumann C \& De La Fuente R 2009 ATRX marks the inactive X chromosome (Xi) in somatic cells and during imprinted $\mathrm{X}$ chromosome inactivation in trophoblast stem cells. Chromosoma 118 209-222. (doi:10.1007/ s00412-008-0189-x)

Baumann C, Viveiros MM \& De La Fuente R 2010 Loss of maternal ATRX results in centromere instability and aneuploidy in the mammalian oocyte and pre-implantation embryo. PLoS Genetics 6 e1001137. (doi:10.1371/journal.pgen.1001137)

Bolton VN, Leary C, Harbottle S, Cutting R \& Harper JC 2015 How should we choose the 'best' embryo? A commentary on behalf of the British Fertility Society and the Association of Clinical Embryologists. Human Fertility 18 156-164. (doi:10.3109/14647273.2015.1072646)

Bradford MM 1976 A rapid and sensitive method for the quantitation of microgram quantities of protein utilizing the principle of protein-dye binding. Analytical Biochemistry 72 248-254. (doi:10.1016/00032697(76)90527-3)

Cheung J \& Smith DF 2000 Molecular chaperone interactions with steroid receptors: an update. Molecular Endocrinology 14 939-946. (doi:10.1210/mend.14.7.0489)

De La Fuente R, Viveiros MM, Wigglesworth K \& Eppig JJ 2004 ATRX, a member of the SNF2 family of helicase/ATPases, is required for chromosome alignment and meiotic spindle organization in metaphase II stage mouse oocytes. Developmental Biology 272 1-14. (doi:10.1016/j. ydbio.2003.12.012)

De La Fuente R, Baumann C \& Viveiros MM 2012 Chromatin structure and ATRX function in mouse oocytes. Results and Problems in Cell Differentiation 55 45-68. (doi:10.1007/978-3-642-30406-4_3)

De La Fuente R, Baumann C \& Viveiros MM 2015 ATRX contributes to epigenetic asymmetry and silencing of major satellite transcripts in the maternal genome of the mouse embryo. Development 142 1806-1817. (doi:10.1242/dev.118927) 
Fair T 2010 Mammalian oocyte development: checkpoints for competence. Reproduction Fertility and Development 22 13-20. (doi:10.1071/ RD09216)

Fair T, Hyttel P \& Greve T 1995 Bovine oocyte diameter in relation to maturational competence and transcriptional activity. Molecular Reproduction and Development 42 437-442. (doi:10.1002/ mrd.1080420410)

Fair T \& Hyttel P 1997 Oocyte growth in cattle- Ultrastructure, transcription and developmental competence. Proceedings of 2nd International Malpighi Symposium, Edited by Motta PM. Univ Rome la sapienza, Rome, Italy 1995. In Microscopy of reproduction and development : a dynamic approach. pp 109-118.

Gibbons RJ, McDowell TL, Raman S, O'Rourke DM, Garrick D, Ayyub H \& Higgs DR 2000 Mutations in ATRX, encoding a SWI/SNF-like protein, cause diverse changes in the pattern of DNA methylation. Nature Genetics 24 368-371. (doi:10.1038/74191)

Kernohan KD, Jiang Y, Tremblay DC, Bonvissuto AC, Eubanks JH, Mann MR \& Berube NG 2010 ATRX partners with cohesin and MeCP2 and contributes to developmental silencing of imprinted genes in the brain. Developmental Cell 18 191-202. (doi:10.1016/j. devcel.2009.12.017)

Lukas J, Lukas C \& Bartek J 2011 More than just a focus: The chromatin response to DNA damage and its role in genome integrity maintenance. Nature Cell Biology 13 1161-1169. (doi:10.1038/ncb2344)

Murga M, Jaco I, Fan Y, Soria R, Martinez-Pastor B, Cuadrado M, Yang SM, Blasco MA, Skoultchi Al \& Fernandez-Capetillo O 2007 Global chromatin compaction limits the strength of the DNA damage response. Journal of Cell Biology 178 1101-1108. (doi:10.1083/ jcb.200704140)

O'Doherty AM, O'Shea LC \& Fair T 2012 Bovine DNA methylation imprints are established in an oocyte size-specific manner, which are coordinated with the expression of the DNMT3 family proteins. Biology of Reproduction 86 67. (doi:10.1095/biolreprod.111.094946)

O'Shea LC, Mehta J, Lonergan P, Hensey C \& Fair T 2012 Developmental competence in oocytes and cumulus cells: candidate genes and networks. Systems Biology in Reproductive Medicine 58 88-101. (doi:10.3109/19396368.2012.656217)

O'Shea LC, Hensey C \& Fair T 2013 Progesterone regulation of AVEN protects bovine oocytes from apoptosis during meiotic maturation. Biology of Reproduction 89 146. (doi:10.1095/ biolreprod.113.111880)
Petrussa L, Van de Velde H \& De Rycke M 2014 Dynamic regulation of DNA methyltransferases in human oocytes and preimplantation embryos after assisted reproductive technologies. Molecular Human Reproduction 20 861-874. (doi:10.1093/molehr/gau049)

Ritchie K, Seah C, Moulin J, Isaac C, Dick F \& Berube NG 2008 Loss of ATRX leads to chromosome cohesion and congression defects. Journal of Cell Biology 180 315-324. (doi:10.1083/jcb.200706083)

Seah C, Levy MA, Jiang Y, Mokhtarzada S, Higgs DR, Gibbons RJ \& Berube NG 2008 Neuronal death resulting from targeted disruption of the Snf2 protein ATRX is mediated by p53. Journal of Neuroscience $\mathbf{2 8}$ 12570-12580. (doi:10.1523/JNEUROSCI.4048-08.2008)

Shufaro Y \& Laufer N 2013 Epigenetic concerns in assisted reproduction: update and critical review of the current literature. Fertility and Sterility 99 605-606. (doi:10.1016/j.fertnstert.2013.01.126)

Teutsch G \& Philibert D 1994 History and perspectives of antiprogestins from the chemist's point of view. Human Reproduction 9 (Supplement 1) 12-31. (doi:10.1093/humrep/9.suppl_1.12)

Trapphoff T, Heiligentag M, Dankert D, Demond H, Deutsch D, Frohlich T, Arnold GJ, Grummer R, Horsthemke B \& EichenlaubRitter U 2016 Postovulatory aging affects dynamics of mRNA, expression and localization of maternal effect proteins, spindle integrity and pericentromeric proteins in mouse oocytes. Human Reproduction 31 133-149. (doi:10.1093/humrep/dev279)

Tsai MJ \& O'Malley BW 1994 Molecular mechanisms of action of steroid/ thyroid receptor superfamily members. Annual Review of Biochemistry 63 451-486. (doi:10.1146/annurev.bi.63.070194.002315)

Voon HPJ \& Gibbons RJ 2016 Maintaining memory of silencing at imprinted differentially methylated regions. Cellular and Molecular Life Sciences 73 1871-1879. (doi:10.1007/s00018-016-2157-6)

Whitelaw N, Bhattacharya S, Hoad G, Horgan GW, Hamilton M \& Haggarty P 2014 Epigenetic status in the offspring of spontaneous and assisted conception. Human Reproduction 29 1452-1458. (doi:10.1093/ humrep/deu094)

Received 10 August 2016

First decision 5 September 2016

Revised manuscript received 3 February 2017

Accepted 28 February 2017 